\title{
LAS AUTONOMÍAS DE LOS PUEBLOS MAYAS DE YUCATÁN Y SU SILENCIO ANTE LAS POLÍTICAS DE ASIMILACIÓN Y LA LEGISLACIÓN DE SUS DERECHOS
}

\author{
Ana Rosa Duarte Duarte ${ }^{1}$ dduarte@uady.mx \\ Universidad Autónoma de Yucatán \\ Unidad de Ciencias Sociales \\ Centro de Investigaciones Regionales «Dr. Hideyo Noguchi» \\ ... el hombre que nos muestra que conoce el ritmo de nuestro silencio \\ está mucho más cerca de nosotros que aquel que cree que sabe hablar.
}

Ivan Illich (2013)

\section{RESUMEN}

En este artículo exploro cómo los mayas yucatecos emplean el silencio como una de las principales estrategias de resistencia a la asimilación, y sugiero que ayuda a explicar su indiferencia a la legislación recientemente aprobada para proteger sus derechos. En parte, baso mi análisis en conversaciones con jóvenes y abuelos, cuyas profecías y prácticas cotidianas contribuyen a la continuada fortaleza de la cultura, de cara a las políticas neocoloniales del presente. La creencia de que «no pasa nada en Yucatán» alimenta la noción de una apatía maya, pero que tiene sus raíces en los discursos oficiales y académicos que históricamente han descartado a los mayas por considerarlos irrelevantes en la esfera pública. Por último, examino cómo los mayas han adaptado sus estrategias para preservar sus autonomías, a pesar de las políticas paternalistas dirigidas a su asimilación.

Palabras clave: autonomía, autosubsistencia, maya, movimientos sociales. 


\title{
THE AUTONOMY OF THE MAYAN PEOPLES OF YUCATAN AND THEIR SILENCE IN RELATION TO ASSIMILATION POLICIES AND THE LEGISLATION OF THEIR RIGHTS
}

\begin{abstract}
In this article the author explores how the Mayans from Yucatan use silence as one of their main strategies to resist assimilation, suggesting that this helps explain their indifference toward the recently approved legislation to protect their rights. Her analysis is based in part on conversations with young people and elders whose prophesies and everyday practices contribute to the ongoing strength of their culture in the face of current neo-colonial policies. The belief that «nothing happens in Yucatan» feeds the notion of the existence of apathy among the Mayans, and has its roots in the official and academic discourses that historically have discarded the Mayans as irrelevant to the public sphere. Lastly, it examines how in spite of the paternalistic policies aimed at assimilation, the Mayans have adapted their strategies in order to preserve their autonomy.
\end{abstract}

Key words: autonomy, self-sufficiency, Mayan, social movements. 


\section{INTRODUCCIÓN}

Parecería paradójico que en la sede de una larga historia conflictiva y del movimiento autonómico más exitoso del siglo XIX y principios del siglo $\mathrm{XX}^{2}$ muchos visitantes ahora me preguntan por qué «no pasa nada», por qué no existen movimientos sociales en el mundo maya peninsular. Durante más de medio siglo, los gobiernos autonómicos mayas mantenían el control del oriente y sur de la península, con sus propias redes de comercio, a la vez que desconocían los gobiernos federales y estatales mexicanos, algunos de ellos hasta la década de 1930 (Wammack y Duarte 2012). Ante los fracasados intentos militares de someter a estos gobiernos autónomos y conquistar su territorio, los gobiernos mexicano y yucateco recurrieron al bloqueo económico y a una amplia gama de estrategias y políticas asimilacionistas, que se agudizaron después de la Revolución. Aun así, una gran parte del pueblo maya siguió la resistencia en silencio, con el resultado de que hoy en día siguen vigentes las prácticas ancestrales y la lengua por toda la península. Pero mientras que existe una amplia bibliografía acerca de los movimientos sociales del mundo maya en Chiapas y Guatemala, las investigaciones en la península de Yucatán han contribuido más bien a construir una representación de los mayas peninsulares como pasivos y sin interés en conocer sus propios derechos. ${ }^{3}$

No obstante, estas representaciones no son desinteresadas, sino que las frecuentes referencias a un pueblo maya pasivo y desinteresado forman parte de un discurso más generalizado, que hace «necesaria» la continuidad del paternalismo y de las políticas asimilacionistas. De hecho, este discurso, con sus múltiples afirmaciones de «aquí no pasa nada», sostuvo la elaboración de la reforma constitucional en materia indígena en el estado de Yucatán, y es uno de los supuestos en que descansa la recién aprobada Ley para la Protección de los Derechos de la Comunidad Maya del Estado de Yucatán de 2011 (de aquí en adelante, Ley Maya). Aun desde los inicios del proyecto de la Ley Maya, un miembro del Senado me informó que en su elaboración no se iba a tratar «la cuestión de autonomía», 
pues, «no es relevante en nuestro estado» (comunicación personal en 2002).

Pero los que hablamos la lengua maya, y estamos cerca del pueblo, escuchamos otra historia, en la que las visiones mayas de autonomía siguen vigentes, a pesar de las reiteradas preguntas: ¿por qué aquí no pasa nada?, ¿por qué el silencio y la pasividad del pueblo ante la situación económica cada vez más difícil? El despertar en la madrugada del 1 de enero de 1994 en San Cristóbal de Las Casas fue una advertencia al mundo entero de que la diversidad y las autonomías sí existen en México, a pesar de las pretensiones y los discursos que pretenden negarlas. Desde ese día, «el silencio de los zapatistas» ha sido y sigue siendo una de sus armas más potentes. ${ }^{4}$

En este artículo argumento que el «silencio» es una de las prácticas autonómicas más importantes también para el pueblo maya peninsular. Lo que me interesa es específicamente «el poder del silencio» adoptado por el pueblo maya y con el cual ha resistido más de 500 años de colonialismo y neocolonialismo (Duarte 2006, Wammack y Duarte 2012). La importancia de considerar el silencio del pueblo maya como una estrategia autonómica responde en parte a la necesidad de cuestionar los estereotipos construidos de los mayas, y preguntar a quiénes sirven estos. Basso (1970) ya abordó el estereotipo del «indio silencioso» en su estudio entre los apaches, y Scollon (1984, citado en Montoya 2000) muestra cómo la «poca iniciativa de los nativos para introducirse a un tema y por hacer pausas más largas en las charlas», les ha merecido la atribución de cualidades como «pasivos, hoscos, retraídos, no cooperativos, perezosos y estúpidos». No debe sorprendernos, pues, que los mayas peninsulares hayan sido blancos de los mismos estereotipos y las atribuciones negativas que les han asignado a otros pueblos originarios.

Aunque ha sido poco tratado como objeto de estudio en las ciencias sociales, ahora se reconoce que el silencio entre los pueblos indígenas tiene diversos matices. Retomando a De Sousa, Montoya (2000: 271) señala que esto se debe a cuatro razones: (1) porque 
constituye una amenaza a las fronteras científicas aceptadas y a los métodos establecidos en la investigación social; (2) porque los científicos sociales tienden a sentir más confianza especulando con palabras que especulando con el silencio; (3) porque no se ha demostrado la utilidad de los estudios del silencio y no va a ser así hasta que se comience a decodificar los ritmos del silencio en las diferentes sociedades; (4) porque la civilización occidental es parcial contra el silencio y esto afecta las preferencias y capacidades de la comunidad científica. Por todas estas razones, Montoya (2000: 266) señala que el silencio puede resultar del silenciamiento, pero también puede formar parte de una estrategia liberadora.

En este artículo analizo el silencio desde sus aspectos liberadores y como una de las estrategias autonómicas del pueblo maya, sin ignorar su carácter multifacético. Coincido plenamente con Ferguson (2003) en que en las ciencias sociales el silencio es generalmente considerado como una incapacidad para hablar, impuesta a los pueblos sin poder, y coincido también con él cuando afirma que el reconocimiento del silencio también puede funcionar como resistencia a la dominación, sobre todo porque abre nuevas e innovadores posibilidades de análisis. ${ }^{5}$ Pero lo que considero aún más importante es que plantea la necesidad de superar el simple dualismo entre sumisión y resistencia, para considerar también los usos del silencio en la constitución de comunidad. En las siguientes secciones exploro estos usos del silencio por parte del pueblo maya peninsular. Me enfoco, en la segunda sección, en las narrativas que niegan las autonomías, presentan la península como una región donde «no pasa nada» para justificar las políticas asimilacionistas, y proceden a legislar los derechos de un pueblo maya en silencio. En la tercera sección contrasto los modos de vida del pueblo maya cuyas autonomías de autosubsistencia están basadas en sus prácticas cotidianas y de autoconsumo, así como en la manera en que las políticas asimilacionistas afectan las visiones de autonomía del pueblo maya. Por último, presento algunas reflexiones finales y recomendaciones. 
DISCURSOS DE DOMINACIÓN, POLÍTICAS DE ASIMILACIÓN Y EL SILENCIO ANTE LA LEY MAYA

\section{A. LOS DISCURSOS OFICIALES}

Desde que Francisco de Montejo logró establecerse en la península de Yucatán y declarar conquistado el territorio en 1542, los conquistadores y sus descendientes han utilizado los discursos oficiales entre sus estrategias de dominación sobre el pueblo maya. Entre estos discursos está «el mito de la completitud» (Restall 2004: 107) que sigue funcionando para promover la creencia de que todo el pueblo maya había sido conquistado y pacificado, aunque nunca fue así. La historiografía reciente muestra cabalmente que el pueblo maya nunca se sometió en su totalidad, sino que, al contrario, explotó diversas estrategias a lo largo de los siglos para reproducir su autonomía, su lengua, su cultura y sus tradiciones (Wammack y Duarte 2012).

En un importante análisis de la historiografía yucateca del siglo XIX y principios del siglo XX, Molina (1992: 190) muestra cómo los historiadores yucatecos construyeron una visión sumamente negativa del pueblo maya, que no sólo justificaba el dominio de los autodenominados «blancos» sobre los nombrados «indios», sino también la apropiación de las tierras del pueblo maya por parte de los «blancos». Tanto Molina como Wammack y Duarte muestran cómo estos discursos, a menudo despectivos y en otros momentos paternalistas, sirven todavía para negar la vigencia de la autonomía maya y justificar el actual trato de los pueblos mayas como minorías en constante necesidad de programas educativos y asistencialistas, y a la vez como «beneficiarios» de estas mismas políticas. Sean como sean las políticas públicas, ${ }^{6}$ lo que ha sido una constante por toda la historia, desde la conquista hasta el presente, es el empleo de las representaciones negativas del pueblo maya como -ignorantes, menores, incapaces, los sin razón, los «pobres», etc.-, para construir un problema en la necesidad de una solución. 
Por otra parte, el pueblo maya siempre ha empleado «el silencio» como estrategia política, ya sea al evitar contacto, retirarse de las negociaciones ante la falta de cumplimiento de la palabra, etc. Como lo destacó un joven durante una conversación reciente, ${ }^{7}$ «no tiene caso hablar con personas que de todas maneras no saben escuchar», refiriéndose a las reiteradas visitas de entrevistadores que llegan a su pueblo para hacerle preguntas a la gente, sin que haya alguna muestra de respeto. Este joven nos remite a Basso (1970: 214), quien advirtió que los etnógrafos y los lingüistas han prestado poca atención a las interpretaciones culturales de los pueblos indígenas y de esta manera han contribuido a silenciarlos. Sin embargo, el silencio también posibilita las acciones cotidianas y, como señala Montoya (2000), socava o imposibilita las relaciones de dominación. Por su parte, Wagner (2012) afirma que el silencio marca una posición frente al papel subordinado que, en nuestro caso, la sociedad yucateca y la mexicana le han intentado imponer históricamente al pueblo maya. La negativa del joven a ser interlocutor con los entrevistadores es un uso del silencio que, de acuerdo con Gray (2012), expresa solidaridad en la experiencia compartida, demuestra la disidencia, facilita y regula las acciones y actividades colectivas.

\section{B. LAS POLÍTICAS DE ASIMILACIÓN}

Durante el gobierno porfirista, una de las estrategias de las elites políticas y religiosas yucatecas en contra de la autonomía de los pueblos mayas, y con fines asimilacionistas, fue el uso de la educación religiosa y secular, que impulsaron con el establecimiento de escuelas hasta en los rincones más apartados de la península (Sullivan 1991, Savarino 1997), para facilitar la penetración del capitalismo. No fueron del todo bienvenidas las escuelas, por lo cual, en el oriente de la península, en 1936, el Ejército federal amenazaba con recurrir a la fuerza, si fuera necesario, «para asegurase de que aceptaran las escuelas federales» a partir de la fecha dictada (Sullivan 1991: 110). La oposición a las escuelas fue en gran parte por la imposición de maestros mexicanos que sólo enseñaron en español, no por la enseñanza per se, pues ya hacía tiempo que las autoridades mayas enseñaban «a algunos niños a leer y a escribir en maya yucateco, para permitir la continuidad de esa 
aptitud tan esencial para los gobernantes mayas» (Sullivan 1991: 107). En otras partes de la península, las escuelas rurales tenían mayor aceptación, a pesar de promover la aculturación ${ }^{8}$ y sustituir la lengua materna por el español, tal como me platicó mi padre su experiencia escolar a principios del siglo XX, en mi pueblo natal, en el noroeste del estado: «Cuando estudiaba, habían dos turnos, por la mañana y por la tarde... La educación no era como ahora, pues había que trabajar y estudiar en español... Estudiar hasta el segundo grado, era como estudiar el sexto ahora...»

Las pretensiones de aculturación y la sustitución de la lengua materna por el español seguían viento en popa casi 70 años después; así lo pude constatar cuando participé en una investigación de campo acerca de la educación indígena en el oriente del estado de Yucatán, a principios de la década de 1980. Observar una clase de educación bilingüe en ese entonces era reconocer la creatividad de los promotores, hablantes nativos de la lengua maya, con el español como segunda lengua. Ellos se encargaban de la educación escolar de los niños, sin contar con libros en lengua maya. Para dar sus clases, los promotores se enfrentaban a dos obstáculos: primero, tenían que leer en español su material de enseñanza, para luego explicar en maya la lección de cada día; segundo, tenían que impartir lecciones que estaban basadas en situaciones que no tenían ninguna relación con la cultura maya y, por lo tanto, no contaban con referentes para comprender bien las lecciones, ni para explicarlas adecuadamente a los alumnos.

Desde entonces, he seguido de cerca el proceso que conlleva la educación escolar bilingüe, como una de las políticas más fuertes de asimilación. En efecto, las políticas educativas y sus pretensiones asimilacionistas no han cambiado sustancialmente desde finales del siglo XIX, a pesar de los diferentes discursos empleados: como el discurso de la modernización desde finales del siglo XIX hasta mediados del siglo XX; el discurso del desarrollo promovido por la ONU desde 1949 hasta finales de la guerra fría (Wammack y Duarte 2010: 29); y el discurso «intercultural» en la actual época de la globalización, que marca el 
retorno de los mayas en los discursos públicos y sobre todo políticos. Pero el retorno de los mayas a los discursos públicos y políticos ha sido en dos formas: como mercantilización de su cultura y, tal como Castellanos lo muestra, como parte de un «proceso civilizador» para transformar al campesinado en un conjunto de sujetos «capaces de satisfacer las demandas del capitalismo global» (2010: 61), principalmente como mano de obra en la industria del turismo peninsular y consumidores a la vez. Así que, a pesar de las buenas intenciones de las políticas educativas y de las autoridades y los maestros involucrados, la educación escolar ha tenido el efecto de socavar la cultura de los pueblos mayas y sustituir sus autonomías por modos de vida dependientes e integrados al mercado.

Pero las políticas de asimilación no solamente funcionan a través de la educación escolar, pues en la actual época de la globalización están complementadas por políticas públicas, que incluyen apoyos económicos, como el PROCAMPO para realizar las labores de la milpa, así como las transferencias económicas condicionadas a resultados positivos en salud, educación y alimentación (como el programa Oportunidades). Tal como me lo platicó un abuelo:

\begin{abstract}
Ahora los gobiernos están dando dinero para que los campesinos realicemos nuestras milpas, pero los montes que nos quedan ya están cansados... los jóvenes ya no quieren trabajar la milpa... Además, lo que producimos lo compran barato y venden caro, por eso los jóvenes mejor se van a trabajar a Playa del Carmen, en Quintana Roo y compran lo que se necesita para comer y vestir.
\end{abstract}

Como se puede percibir en este fragmento de la conversación, siguen intentando desmantelar las bases de la autonomía en los pueblos mayas, a través de las múltiples estrategias asimilacionistas e integracionistas emprendidas en Yucatán desde finales del siglo XIX y principios del XX, pero también a través de la colonización de sus tierras para la agricultura intensiva, la ganadería, la explotación de los recursos forestales y, desde la década de 1970, el desarrollo de la industria del turismo (Wammack y Duarte 2012: 190). 
Sin embargo, si suponemos que todos han caído en la trampa, estaríamos equivocados, pues la población más joven no se deja engañar tan fácilmente:

Parece que los que históricamente han intentado controlar nuestras vidas, tienen miedo de reconocer nuestro derecho a la libre determinación y autonomía, pues siempre piensan que podemos hacer revueltas... No sabemos qué tienen en la cabeza (Rosa, trabaja en un hotel en Playa del Carmen, Q. Roo).

Lo que nunca van a entender, porque tampoco les interesa, es que nosotros no sólo vivimos de lo que ellos nos quieren dar, sino que también pensamos, sentimos, sabemos y vivimos a diario... (Paula, estudiante de la licenciatura en Lingüística y Cultura Maya).

Si en verdad quieren cambiar, los políticos deberían dejarnos vivir y dedicarse a trabajar otros asuntos de interés para la sociedad (José, trabajador de la milpa y exmigrante, ayudante de jardinería en Playa del Carmen, Q. Roo).

Siempre pienso que a los políticos sólo les importan sus beneficios, porque para ellos no somos nadie (Flor, ayudante de cocina en un hotel de Playa del Carmen, Q. Roo).

Estos fragmentos de conversaciones muestran por qué tantas personas del campo, y de todas las edades, dicen con tanta facilidad: «para el gobierno mix máak'oon» (no somos nadie, somos los invisibles, etc.). A pesar de que estos jóvenes trabajan dentro de las estructuras del sistema económico vigente, no han perdido su cultura ni sus visiones de autonomía; trabajan no sólo para sobrevivir y consumir, sino para lograr que sean cada vez más exitosas las fiestas de los Santos Patronos de sus pueblos, las ceremonias familiares y, en muchos casos, sus milpas y sus ranchos. Esto nos lleva a reconocer la capacidad del pueblo maya para construir nuevas relaciones con la sociedad, y también su disposición de tejer nuevas redes interculturales.

\section{EL PUEBLO MAYA ANTE LA ELABORACIÓN DE LA LEY MAYA}

Tenemos 500 años resistiendo el yugo y todavía ustedes nos ven como si fuéramos retrasados mentales, 
como niños que no podemos caminar, que no podemos llevar nuestro proyecto. ¿Por qué nos quieren diseñar programas detrás de un escritorio y nunca van a pedirnos nuestra opinión?

Faustino Santiago, indígena mixteco, frente a los Senadores de la República el 25 de julio del 2001 (citado en López 2002)

Cuando en 2005 les preguntaba a los jóvenes, adultos y abuelos si sabían que se estaba elaborando una nueva legislación en defensa de sus derechos, ellos simplemente dijeron: «nadie nos preguntó a nosotros». Este fue el contexto del silencio y la apatía que el pueblo maya guardó durante el proceso de aprobación de la Ley Maya en 2011 y su entrada en vigor en 2012. Desde luego, la reforma constitucional en materia de derechos indígenas en los tres estados peninsulares no fue por iniciativa del pueblo maya, ni por el gusto de las elites peninsulares, sino por mandato del Convenio 169 sobre Pueblos Indígenas y Tribales en Países Independientes, adoptado por la Conferencia Internacional del Trabajo de la OIT en junio de 1989, su ratificación por el Gobierno Mexicano en 1992, la firma de los Acuerdos de San Andrés Larráinzar entre el gobierno federal mexicano y el Ejército Zapatista de Liberación Nacional en febrero de 1996 y las reformas a la Constitución Política de los Estados Unidos Mexicanos en 2001, las cuales delegaron la responsabilidad a cada estado. Este mandato creó un problema para las elites de los estados peninsulares, el cual resolvieron cada quien a su manera, en gran parte «detrás de un escritorio» sin involucrar al pueblo maya, supuesto beneficiario de la legislación.

En Yucatán se realizaron tres «consultas» a marchas forzadas durante las últimas semanas del plazo de aprobación. Las pocas personas que asistieron a dichas consultas fueron invitadas y les organizaron el viaje. ${ }^{9}$ Así lo pude constatar el segundo día de consulta, en el sur de Estado, donde participé como especialista en los estudios de la cultura maya. En la Sala se habían reunido aproximadamente 150 personas de los pueblos cercanos, acompañados por funcionarios. Una vez cumplido el protocolo, a los asistentes de las 
poblaciones les entregaron cuatro tacos de cochinita pibil, ${ }^{10}$ acompañados de una bolsa de jugo, mientras que los funcionarios e invitados especiales se fueron a un almuerzo en un conocido restaurante de la misma población. De acuerdo con otro compañero del equipo de investigación, en la primera consulta llevada a cabo en el oriente del Estado asistieron aproximadamente 200 personas de diferentes poblaciones, movilizadas por los funcionarios municipales y locales. La tercera reunión se llevó a cabo en la ciudad de Mérida, con una asistencia de aproximadamente 300 personas, trasladadas de la misma manera que las anteriores.

Difícilmente se puede declarar legitimado un proceso legislativo con tan poca participación y en las condiciones en las que se llevaron a cabo estas reuniones. Pero aun así, el silencio del pueblo maya ante el proceso legislativo ha sido cuestionado: ¿por qué los pueblos mayas no se involucran en la lucha por la legislación de sus derechos? Esta es una pregunta que siempre me han hecho y también fue planteada durante una conferencia magistral acerca de los derechos indígenas en México (Gómez 2010), que curiosamente fue organizada en la ciudad de Mérida como un gesto a las raíces mayas, en el marco de la celebración del «Año de la Patria, Bicentenario del inicio de la Independencia y Centenario de la Revolución», en septiembre de 2010. Ya no nos debemos sorprender que en 2012, «Año Internacional de la Cultura Maya», los pueblos mayas siguieran guardando silencio, en medio de un sinnúmero de actividades celebradas en su nombre, en un festejo que Jaime Novelo, entre otros, describen como la mercantilización de la cultura ${ }^{11}$ maya.

Como parte de una investigación colectiva para observar el proceso legislativo durante la elaboración de la Ley Maya ${ }^{12}$, entre 2006 y 2010 conversé con jóvenes maya hablantes de las comunidades rurales del estado y grabé en video y audio sus opiniones acerca de las diversas propuestas legislativas. Mis principales preocupaciones en estas conversaciones fueron los derechos a la autonomía, al territorio, a los recursos naturales y a los medios. Entre las respuestas que me dieron se encuentran las que siguen: 
Nacho: -La autonomía es cuando podemos decidir sobre nuestra vida y cómo vivirla, pero eso ya no es posible si tienes que trabajar en los hoteles o comercios en Mérida o en la Riviera Maya. Todavía como albañil se puede decidir si quieres ir a trabajar o no.

Beto: -Yo soy agrónomo, pero en vez de trabajar como agrónomo, yo estoy trabajando en mi pueblo, por los derechos de mi pueblo y nuestra cultura, pues como agrónomo no se puede.

Lupe: -La autonomía es como vive uno cada día, cuando puedes decidir lo que quieres hacer, yo soy promotora cultural y ¿̇las leyes? Ni las autoridades las cumplen.

Juan: -La autonomía de nosotros en el pueblo no les interesa a los políticos.

María: -Creo que está bien que hagan algo acerca de las leyes y que lo cumplan, pero la autonomía es la libertad por la que trabajamos todos los días.

Juana: -Yo no entiendo qué es autonomía, pues yo vivo como pueda; con mi familia decidimos siempre qué hacer.

Estas y otras expectativas expresadas durante nuestras conversaciones son bastante heterogéneas, pero todas coinciden al expresar sus preocupaciones acerca de los derechos a la libre determinación, al ejercicio de su autonomía y al disfrute del territorio -derechos que no están considerados en la actual Ley Maya-. Esta ley, además de ignorar todos estos reclamos y recomendaciones del pueblo maya y las organizaciones internacionales, ${ }^{13}$ se limita a crear una figura jurídica «opcional» del «Juez Maya» para la resolución de conflictos internos, a redefinir al pueblo maya yucateco como «las minorías mayas» y declarar que son «más bien mestizos» (H. Congreso del Estado de Yucatán, 2011: 3-6), en contraste a los mayas de Campeche y Quintana Roo. Dicho de otra manera, en lugar de garantizar los derechos del pueblo maya a la libre determinación, autonomía, y territorio, la Ley Maya entrega la «comunidad maya» al Instituto para el Desarrollo de la Cultura Maya del Estado de Yucatán (INDEMAYA) para su administración, preservación y desarrollo (ibid: 18-21). 
Ahora bien, es de suma importancia preguntarnos si esta nueva Ley Maya no es simplemente un mecanismo más del neocolonialismo. Por un lado, no garantiza la libertad de los pueblos mayas para decidir sus formas internas de convivencia, organización social, económica, política y cultural, tal como está estipulado en la Constitución nacional. Por otro lado, corre el riesgo de consagrar, tanto el cliché del mestizaje en general, como el esquema del «mestizo» que se ha vuelto una masa nacional que oculta a los indígenas (Martínez 2007: 156). Asimismo, en un importante estudio acerca de la autonomía como paradigma, Burguete (2009: 86) argumenta que el reconocimiento multicultural de los reclamos por la autodeterminación la han usado los estados de la República mexicana como un recurso para «rearticular su hegemonía y administrar la diversidad», y de esta manera crear una especie de «gobernabilidad multicultural». En este sentido, el estado yucateco suele pedir la colaboración de algunos intelectuales mayas con formación académica para que participen en la gobernabilidad multicultural, pero al mismo tiempo limita su participación para que sirva a los intereses del estado, no a los intereses del pueblo maya.

Por ejemplo, buscaron expertos en lingüística maya para hacer la traducción de la Ley General de Derechos Lingüísticos de los Pueblos Indígenas al idioma maya yucateco (Briceño 2004). Sin embargo, al platicar acerca de esta traducción con María, una joven maya hablante que trabaja como promotora comunitaria, comentó lo siguiente:

¿Qué relación tiene la traducción de esta ley con nuestras expectativas y deseos como parte del pueblo maya? [...] cuando presenté este libro en las escuelas con educación bilingüe, algunos niños me preguntaron, ¿̇a quién le interesa leer maya?, pues yo quiero aprender español». Para María, su experiencia acerca de los eventos académicos y políticos, donde siempre se dice que a los Mayas hay que enseñarles las leyes para que conozcan sus derechos y para que los puedan exigir, ella se pregunta: «¿̇a quién le vamos a exigir? 


\section{LA AUTOSUBSISTENCIA DEL PUEBLO MAYA COMO PRÁCTICA AUTONÓMICA}

Durante la elaboración de la Ley Maya se insistió en que el tema de la autonomía no es relevante en el estado, como ya he señalado, pero los que hablamos maya y estamos cerca del pueblo, escuchamos otra historia, en la que las visiones de autonomía siguen vigentes. Sin embargo, estas visiones no tratan de autonomías formales con sus propios gobiernos, ni de sistemas de soberanía, sino de autonomías de autosubsistencia vinculadas a otra manera de ver el mundo, tal como se destaca en las palabras de un abuelo. Después de un largo suspiro y un buen rato mirando al cielo, predijo: «te digo que... llegará el día en que el rey de los pobres de Cobá gane la guerra contra el rey de los ricos de Chichén Itzá». ${ }^{14}$

Parafraseando a De Sousa (2010), sugiero que esta y muchas otras profecías mayas son expresiones de lo que él llama «un sentimiento de urgencia» ante el inminente colapso del mundo que conocemos. Tanto De Sousa como los abuelos, cuyas entrevistas en lengua maya grabé en video y audio, coinciden en advertir que los efectos de la crisis del sistema político económico actual son cada vez menos tolerables. Sin embargo, mientras que las profecías de nuestros abuelos prevén el colapso del sistema debido a los conflictos entre los mismos poderíos que lo han impuesto, De Sousa considera necesario, primero, construir un mundo diferente para dar cabida a un mundo en el que la diversidad y la autonomía fueran posibles.

Estas visiones parten de concepciones de autonomía que son fundamentalmente distintas, pues a pesar de que De Sousa y los abuelos coinciden en la «no» sustentabilidad del actual sistema geopolítico, De Sousa habla desde ese sistema que siempre ha excluido la diversidad, mientras que los abuelos hablan desde la diversidad que aquel sistema ha intentado excluir y desde las autonomías que el mismo sistema siempre ha negado. Dicho de otra manera, los abuelos, que cito en este artículo hablan desde un mundo que ni la conquista ni la pacificación ni la colonización ni el paternalismo ni el neoliberalismo ni el 
mercado libre han podido eliminar, tal como lo han señalado Wammack y Duarte (2012), entre otros autores.

La autonomía del pueblo maya yucateco se expresa hoy en día en un «sustrato común», lo que les permite comunicarse e identificarse en cualquier lugar de la península, el Petén y partes de Belice y Chiapas. Este sustrato común está compuesto por la lengua, la cultura, los rituales, así como la organización social y política (Villalobos 2006). Pero también forman parte de este sustrato común las actividades de autoconsumo, basado en la milpa, la caza, la recolección y la comida, las cuales lo sustentan, y esto permite a cada grupo doméstico una gran movilidad y autonomía (Wammack y Duarte 2012: 191-192).

No se trata solamente de una autonomía basada en principios igualitarios, participativos, autogestivos y colectivos, como la define López y Rivas (2005), sino de «autonomías de autosubsistencia» que consisten en modos de vivir en que se aglutinan múltiples actividades cotidianas, desde el trabajo de milpero y la preparación de las tortillas hasta la emigración a otros centros de trabajo (Wammack y Duarte 2012: 191-192). Al contrario de lo que plantea Aparicio (2009), la autonomía maya no es únicamente una forma de organización al margen, o parcialmente al margen de los esquemas de la sociedad dominante, sino también permea a estos mismos esquemas. Por ello, «el silencio» ha funcionado como una de las más importantes prácticas autonómicas y también como estrategia política ancestral, pero actual a la vez, ya que no es necesario anunciar la autonomía, sino practicarla. Por lo tanto, la defensa del territorio ha sido una contante en la vida del pueblo maya, incluso durante el gobierno de Felipe Carrillo Puerto y el cardenismo. ${ }^{1}$ Por ello, el pueblo maya ha roto el silencio una y otra vez, manifestándose contra las violaciones de sus derechos y los despojos de sus tierras hasta al menos en la década de 1970.

Los pueblos mayas han emprendido, desde siempre, una serie de prácticas organizativas y 
de autoconsumo que les han permitido reproducir sus modos de vida de manera autónoma, ya sea como grupo doméstico, comunidad o pueblo. Estas prácticas autonómicas siempre han dado la fortaleza a los pueblos mayas para resistir la negación y la invisibilización, y han mostrado una clara capacidad para mantener y fortalecer su identidad cultural. Las visiones de autonomía que actualmente comparten se basan tanto en la lengua maya como en las actividades productivas tradicionales y no tradicionales. Actualmente más de 50\% del pueblo maya aún usa su lengua materna, la maya yucateca, para comunicarse cotidianamente, y por ello el número de maya hablantes es el segunda después del náhuatl.

Las visiones de autonomía tienen sus bases propias, pues aun en el siglo XXI, más de 100,000 milperos mayas en la península se dedicaban a la milpa tradicional en 2006, con más de 300,000 hectáreas en cultivo. Los pueblos mayas desempeñan una gran diversidad de actividades: albañiles, estudiantes, profesionistas, pequeños y grandes empresarios, artistas, músicos, médicos, parteras, constructores e ingenieros, profesores y maestros, curanderos, j'meno'ob, ${ }^{15}$ políticos, obreros, artesanos, escritores, poetas, apicultores, ganaderos y agricultores, entre otros (Wammack y Duarte 2010: 21).

La vida cotidiana de los pueblos mayas está encaminada a ejercer el derecho de ser y hacer, más allá de normas y reglas impuestas por la sociedad, ya sea colonial, moderna o global. Se trata de su quehacer cotidiano por su reconocimiento como diferencia y su diversidad, pues el reconocimiento de los pueblos mayas actuales y su resistencia «no es para entronizarlo ni para totalizarlo», es simplemente para asumir su vigencia (Martínez 2007: 162). Reconocer las diferencias de los pueblos mayas es permitir que seamos libres para decidir nuestras propias formas de organización social y política, con una capacidad productiva con y a pesar de otras maneras de organización social y política de la sociedad en general.

Las relaciones interculturales dependen de la voluntad de todos los sujetos que se 
constituyen en cada cultura para poder interaccionar, y no solo de los instrumentos creados para ello (Pérez y Argueta 2011). Es necesario también asumir que el pueblo maya es heterogéneo, como cualquier otro pueblo. Caracterizar a los mayas como débiles, pobres o ignorantes debido a sus diferencias en sus modos de vida, y legislar sobre una «igualdad» no significa que vayan a superarse las diferencias y mucho menos que se vaya a construir una estructura para una relación intercultural.

Las autonomías de autosubsistencia se construyen con el paso del tiempo y se nutren de las prácticas de los sujetos autonómicos que se constituyen para garantizar la continuidad de dichas prácticas. Es así que, ante la falta de voluntad política de los Estados, de la sociedad mexicana y de la yucateca en particular, una importante parte del quehacer de los pueblos mayas para mantener su autonomía es a través del silencio, tal como indican los abuelos:

aquí nadie nos va a venir a decir lo que tenemos que hacer, pues nosotros estamos acostumbrados a decidir lo que nos conviene, sin poner en riesgo a nuestras familias y a nuestra población.

hace más de dos siglos que se acabó nuestra disposición a dialogar, pues aprendimos que siempre prometen y ya sabemos por siglos que nunca cumplen.

Los programas de apoyo que lleguen, bienvenidos, pues es la obligación de los gobiernos mantener la paz social frente a la guerra que nos han declarado desde hace más de dos siglos, con los reiterados despojos de nuestros propios recursos para producir nuestros alimentos.

Una lectura hecha desde la diferencia nos lleva a reconocer que la tolerancia, la paciencia, la observación y el silencio han sido las principales armas del pueblo maya a lo largo de la historia. Y mientras que para algunos estudiosos el empleo de estas armas, que no caben fácilmente en el paradigma de los movimientos sociales, es entendida solo como muestra de debilidad y de una falta o la ausencia de demandas, el pueblo maya sigue utilizando el silencio para expresar su posición frente al incumplimiento de la palabra y en defensa de su 
autonomía.

\section{REFLEXIONES FINALES}

En este artículo he argumentado que el silencio ha sido una de las principales estrategias de vida del pueblo maya yucateco, y que esta no sólo ha contribuido a la permanencia de la autonomía maya hasta nuestros días, sino que también explica, en gran parte, la falta de participación del pueblo maya en el proceso legislativo, que ostensiblemente fue dirigido a la protección de los derechos mayas en el estado de Yucatán. En el artículo me basé, en parte, en las conversaciones que he tenido con abuelos y jóvenes mayahablantes, y propuse que sus profecías, percepciones y prácticas cotidianas contribuyen a la resistencia de la cultura, frente a las políticas colonialistas y neocolonialistas.

La segunda parte del artículo examina cómo fue construida la visión negativa de los pueblos mayas de Yucatán y quiénes participaron en ella. Desde esta visión, las elites yucatecas, apoyadas por el aparato intelectual, han sustentado las políticas asimilacionistas y han pretendido silenciar a los pueblos mayas e invisibilizar sus modos de vida y sus autonomías. La cultura de los pueblos mayas tiene una base en las autonomías de autosubsistencia, lo que se sustenta en el substrato de la lengua, la cultura, los rituales, la organización social y política, así como en las prácticas de subsistencia como la milpa, la caza y los animales domésticos.

He puesto especial atención en cómo y cuáles son las actuales prácticas que sustentan a las autonomías de autosubsistencia y las visiones que los pueblos mayas tienen de su autonomía. La persistencia de actitudes, símbolos y recuerdos en las manifestaciones populares no son residuos ancestrales, como se cree en la sociedad yucateca, sino una manera de ser que se renueva en el espíritu vivo de la cultura, en la tradición y en el cambio comunitario para enseñar que el progreso económico, al precio de la destrucción humana y planetaria, no tiene por qué ser el destino único y fatal (Martínez 2007: 150). 
La principal preocupación que históricamente ha sido planteada por el Estado es la necesidad de integrar a los pueblos mayas a la nación, originalmente concebida como monocultural y ahora como pluricultural, pero sin el derecho a la autonomía. Hoy en día, el Estado está procurando acabar con las autonomías de autosubsistencia, a través de prácticas de mercado (neoliberales) apoyadas en una ideología de «igualdad», materializándose en la vida cotidiana como discriminación, tal como señala Ayala (1995). El Estado también propone que haya una relación intercultural, pero sobre la base de la discriminación, la negación de la libre determinación y la negación al derecho a la autonomía.

Finalmente argumento que la histórica falta de voluntad del Estado para cambiar sus relaciones con el pueblo maya ha llevado al pueblo a utilizar el silencio para posicionarse ante la negación de sus derechos y la negación a decidir sus propias políticas de desarrollo, sus formas de vida, y su organización social y cultural basada en sus propios modos de vida.

Con base en los argumentos desarrollados a lo largo de este artículo propongo que:

(1) En la legislación se reconozca el derecho de los pueblos mayas a la libre determinación y a decidir sus propias estrategias de desarrollo, pues son precisamente los que viven y conviven con todo lo que les rodea.

(2) La enseñanza del idioma maya sea obligatorio en todos los niveles educativos en Yucatán, sin exentar a las escuelas privadas, no sólo para la educación indígena, pues de lo contrario la enseñanza del idioma maya se basa en la discriminación y funciona principalmente para facilitar la transición al español. 


\section{FUENTES DE CONSULTA}

Aparicio Wilhelmi, Marco, 2009, «La libre determinación y la autonomía de los pueblos indígenas. El caso de México», Boletín Mexicano de Derecho Comparado, n. 124. UNAM, México, http://biblio.juridicas.unam.mx/revista/DerechoComparado/ indice.htm [consulta: 5 de noviembre de 2012].

Ayala Corao, Carlos M., 1995, «El Estado constitucional y autonomía de los pueblos indígenas», Serie estudio de derechos humanos. n. 3, pp. 397-423. biblio.juridicas.unam.mx/libros/4/1836/29.pdf [consulta: 24 de enero de 2012].

Basso, Keith H., 1970, «To give up on words: Silence Apache Culture», Southwestern Journal of Anthropology, v. 26, n. 3, pp. 213-230, http://www.jstor.org/stable/ 3629378 [consulta: 30 de julio de 2013].

Briceño Chel, Fidencio, 2004, Noj a’almaj t’aanil u páajtalil u t’a’anal máasewal t’aano’ob ich Maaya yéetel kásstlan t’aan. Ley General de Derechos Lingüísticos de los Pueblos Indígenas en Maya y Español, Conaculta, INAH, Mérida.

Burguete Cal y Mayor, Araceli, 2009, «Autonomía: la emergencia de un paradigma en las luchas por la descolonización en América Latina», en La autonomía a debate autogobierno indígena y estado plurinacional en América Latina, coordinado por González, Miguel, Araceli Burguete Cal y Mayor y Pablo Ortiz-T, FLACsO, Quito.

Castellanos Chávez, María Bianet, 2010, «Género y migración: la globalización del campo rural y la invención de Cancún», en Género en la época de la globalización. Una mirada desde el Mundo Maya, editado por Duarte Duarte, Ana Rosa y Byrt Wammack, Plaza y Valdés, México, pp. 53-78.

Duarte Duarte, Ana Rosa, 2006, «Espíritu de lucha: cuerpo, poder y cambio sociocultural». Tesis de doctorado, UAM, México.

Duarte Duarte, Ana Rosa y Byrt Wammack Weber, 2010, Género en la época de la globalización. Miradas desde el mundo maya, Plaza y Valdés, México.

De Sousa Santos, Boaventura, 2010, Para descolonizar Occidente. Más allá del pensamiento 
abismal, Consejo Latinoamericano de Ciencias Sociales (CLACSO), Buenos Aires.

Ferguson, Kennan, 2003, «Silence: A Politics», Contemporary Political Theory, v. 2, n. 1, pp. 49-65.

Gómez Rivera, Magdalena, 2010, «Los derechos indígenas en México (1992-2001). Elementos para un balance», conferencia magistral presentada dentro del Seminario Permanente «El pueblo maya y la sociedad regional», CIESAS Peninsular, Mérida.

Gómez, Yásser, 2010, «Para los zapatistas es importante el silencio como estrategia de lucha/Xóchitl Leyva Solano» en http://sangreenlasideas.blogspot.mx/2010/08/paralos-zapatistas-es-importante-el.html [consulta: 20 de noviembre de 2012].

Gray, Sean, 2012, «Silent Citizenship in Democratic Theory and Practice: The Problems and Power of Silence in Democracy», APSA 2012 Annual Meeting Paper, Social Science Research Network, U.S.A., en http://ssrn.com/abstract=2104876 [consulta: 1 de octubre de 2013].

H. Congreso del Estado de Yucatán, 2011, «Ley para la Protección de los Derechos de la Comunidad Maya del Estado de Yucatán», Diario Oficial del Gobierno del Estado de Yucatán, año CXIV, n. 31, Mérida.

Illich, Ivan, 2013, «El silencio de los Zapatistas», Locomotor, La agenda cultural, en http://www.locomotor.mx/elsilencio-de-los-zapatistas/ [consulta: 1 de octubre de 2013].

López Bárcenas, Francisco, 2002, Los derechos indígenas y la reforma constitucional en México, Universidad de Texas, Austin.

López y Rivas, Gilberto, 2005, «México: las autonomías de los pueblos indios en el ámbito nacional», en Autonomías indígenas en América Latina: nuevas formas de convivencias política, editado por Gabriel, Leo y Gilberto López y Rivas, Plaza y Valdés, México, pp. 47-111.

Marín Beristain, Carlos, Darío Paez y José Luis González, 2000, «Rituals, social sharing, silence, emotions and collective memory claims in the case of the Guatemalan genocide», Psicothema, v. 12, suplemento 1, pp. 117-130. 
Martínez Terán, Teresa, 2007, «El imaginario del colonizador», Argumentos, v. 20, n. 53. UAM-X, México, pp. 143-167.

Molina Ludy, Virginia, 1992, «La imagen del indio maya en los historiadores yucatecos del siglo XIX», Mayab, n. 8, Sociedad Española de Estudios Mayas, Instituto de Cooperación Iberoamericana, pp. 183-191.

Montoya, Margaret E., 2000, «Silence and Silencing: Their Centripetal and Centrifugal Forces in Legal Communication, Pedagogy, and Discourse», Michigan Journal of Law Reform, v. 33, pp. 263-296.

Pennebaker, James W., Tracy J. Mayne y Martha E. Francis, 1997, «Linguistic Predictors of Adaptive Bereavement», Journal of Personality and Social Phychology, v. 72, n. 4, $\quad$ pp. 863-871, en http://homepage.psy.utexas.edu/homepage/faculty/pennebaker/reprints/PMayne19 97.pdf [consulta: 30 de julio de 2013].

Pérez Ruiz, Maya Lorena y Arturo Argueta Villamar, 2011, «Saberes Indígenas y Diálogo intercultural», Cultura científica y saberes locales, año V, n. 10, pp. 31-56.

Restall, Matthew, 2004, Los siete mitos de la conquista española, Paidós, Barcelona. Savarino Roggero, Franco, 1997, «Religión y Sociedad en Yucatán durante el Porfiriato (1891-1911)», Historia Mexicana, v. 46, n. 3, El Colegio de México, Centro de Estudios Históricos, México, pp. 617-651.

Scollon, R. y S. Scollon, 1984, «Cooking up and boiling down: Abstracts in Athabascan Children's story retellings», en Coherence in spoken and written discourse, editado por Tannen, Deborah, Ablex Publishing Corporation, Norwood, Nueva Jersey, pp. 173-197.

Scott, James C., 1985, Weapons of the weak. Everyday forms of the peasant resistance. Yale University, EUA.

Sullivan, Paul, 1991, Conversaciones inconclusas: Mayas y extranjeros entre dos guerras. Gedisa, México.

Villalobos González, Martha Herminia, 2006, El bosque sitiado: asaltos armados, 
concesiones forestales y estrategias de resistencia durante la Guerra de Castas. CIESAS, México.

Wagner, Roi, 2012, «Silence as Resistance before the Subject, or Could the Subaltern Remain Silent?», Theory, Culture \& Society, SAGE-Journals, v. 29, n. 6, pp. 99124.

Wammack Weber, Byrt y Ana Rosa Duarte Duarte, 2012, «Mayan Visions of Autonomy and the Politics of Assimilation», en Comparative Indigeneities of the Americas, editado por Castellanos, M. Bianet, et al., The University of Arizona Press, Tucson, pp. 184-197.

Wammack Weber, Byrt y Ana Rosa Duarte Duarte, 2010, «Género y globalización. Un panorama intercultural», en Género en la época de la globalización. Miradas desde el Mundo Maya, editado por Duarte Duarte, Ana Rosa y Byrt Wammack, Plaza y Valdés, México, pp. 15-49.

Warnholtz Locht, Margarita, 2008, «Poblaciones y lenguas indígenas de México: una riqueza difícil de cuantificar», Mundo indígena, n. 2, suplemento del Diario Milenio y SEPRADI, México, en http://www.redindigena.net/mundoindigena/n2/pag1.html [consulta: 3 de agosto de 2013].

\section{NOTAS}

\footnotetext{
${ }^{1}$ La autora de este artículo desea agradecer la beca de viaje para hacer Investigación en la Colección Latinoamericana, Nettie Lee Benson y LLILAS, que le otorgó la Universidad de Austin en Texas, para realizar su estancia del 15 al 31 de enero de 2013, de la cuál resultó gran parte de la bibliográfica utilizada en este artículo.

${ }^{2}$ El movimiento autonómico va más allá del movimiento armado de 1847 y acuñado en la literatura como «Guerra de Castas». Se trata más bien de las estrategias de lucha constante, como replegarse a la montaña, o monte alto, en contra de las múltiples invasiones del Ejército mexicano a las poblaciones, para convertir a los pueblos en ciudadanos (véase Wammack y Duarte 2012).

${ }^{3}$ A mi parecer, la pregunta ¿por qué los pueblos mayas no se involucran en la lucha por la legislación de sus derechos?, que surgió durante la conferencia magistral «Los derechos indígenas en México (1992-2001). Elementos para un balance», dictada por la Mtra. Magdalena Gómez Rivera, en septiembre de 2010, en CIESAs Peninsular, Mérida, Yucatán, está basada en una interpretación del silencio como: los mayas pasivos, tontos, ignorantes, etcétera.
} 
${ }^{4}$ Se ha escrito mucho acerca del silencio de los zapatistas y su empleo como estrategia política. Véase, por ejemplo, Xóchitl Leyva Solano, quien durante una entrevista para Radio Proletaria 107.5, el 17 de agosto de 2010 señaló que para los zapatistas es importante el silencio como estrategia de lucha política (Gómez 2010).

${ }^{5}$ Entre algunos ejemplos de trabajos que tratan las diversas maneras de entender el silencio se pueden mencionar: el silencio como respuesta a la represión o estrategia adaptativa para la supervivencia que está en Marín et al. (2000); el silencio como inhibición ante eventos traumáticos en Pennebaker et al. (1997) y el silencio como acciones de resistencia a normas en la vida cotidiana en Scott (1985).

${ }^{6}$ Las políticas asimilacionistas o integracionistas son como las escuelas públicas que se establecieron para acabar con la ignorancia de los indios; hasta los diversos Programas de desarrollo desde los setenta, entre ellos las Unidades Agrícolas e Industriales para la Mujer (UAIM), el Programa de Apoyo Directo al Campo, PROCAMPO y el Programa de transferencia económica para asegurar mejores niveles de Educación, Salud y Alimentación, PROGRESA y ahora Oportunidades.

${ }^{7}$ Esta conversación se llevó a cabo en la Unidad de Ciencias Sociales del Centro de Investigaciones Regionales «Dr. Hideyo Noguchi» de la Universidad Autónoma de Yucatán, donde nos reunimos estudiantes del Verano de la Investigación 2013 y tesistas, para discutir el concepto de saberes en la cultura maya, en relación con los saberes en la academia.

${ }^{8}$ La aculturación se entiende como los procesos en los cuales los individuos tienen que volver a hacerse parte de una cultura diferente a aquella en la que fueron originalmente preparados.

${ }^{9}$ Para hablar de pocas personas me baso en los datos poblacionales publicados en Mundo Indígena, suplemento del diario Milenio de 2008, en el cual se muestra que había una población de 1,475,575 mayas en la península de Yucatán, según datos tomados del INALI, INEGI Y CDI (Warnholtz 2008).

${ }^{10}$ Es un guisado preparado de carne de cerdo, condimentado con achiote y hojas de plátano, y es cocido en el pib. El pib consiste en preparar un horno en la tierra, donde se hace una excavación y luego le colocan la leña y piedras. Una vez que se consumió la leña, quedan las piedras candentes, sobre las cuales colocan el traste de la carne y tapan el hoyo con palos, hojas verdes y tierra encima. Dos horas después ya estará cocido y lo retiran del pib listo para servirlo. En los medios urbanos se cocina la cochinita en el horno de las estufas.

${ }^{11}$ La mercantilización de la cultura maya a la que se refirió específicamente el Prof. Jaime Ermilo Novelo González, jefe del Departamento de Educación Inicial y Preescolar de la Secretaría de Educación Indígena de la Secretaría de Educación Pública en Yucatán, durante su conferencia en la III Mesa Panel, «Bejlae' maayao'b ku t'aano'ob / Los mayas tienen la palabra», son los festejos que las instituciones de gobierno organizaron a nombre del pueblo maya en Mérida, a finales del año 2012. Cuando se habla de la mercantilización de la cultura maya se hace referencia a un descontento generalizado (entre aquellos que nos reconocemos como parte del pueblo maya y aquellos que se identifican con la cultura maya), ante los festejos encaminados a exhibir a los mayas como atractivos para el turismo, festejos en los cuales, los que menos importan son los pueblos mayas.

${ }^{12}$ Se trató de una investigación colectiva que concluyó en 2011 y que llevó el título «La cultura maya yucateca ante las modificaciones constitucionales y legales en proceso», dirigido por Esteban Krotz, en la cual participamos Amarella Eastmond, Alejandra García Quintanilla, Miguel Güemes Pineda, Hilaria Máas Collí y la autora de este artículo. El objetivo del proyecto fue monitorear el proceso legislativo acerca de los derechos del pueblo maya en el estado de Yucatán y analizar sus efectos en los ámbitos temáticos de cada uno de los integrantes del Cuerpo Académico «Identidad y Cultura Maya en Yucatán».

${ }^{13}$ Instituciones internacionales como Derechos Humanos, Convenio 169 de la OIT, el Convenio Constitutivo del Fondo para el Desarrollo, e incluso la Ley COCOPA y el catálogo de derechos de la ONU.

${ }^{14}$ Fragmento de mis conversaciones personales con un abuelo en 2003. 
${ }^{15}$ Son personas con dones especiales para curar y realizar ceremonia en bien de sus comunidades, pero que muchas veces son confundidos con chamanes o sacerdotes.

Fecha de recepción: 15 de diciembre de 2012.

Fecha de aceptación: 11 de agosto de 2013. 